\title{
FIRE PREVENTION
}

\section{By Everett U. Crosby,}

General Agent North British and Mercantile Insurance Company and Chairman of the Executive Committee of the National Fire Protective

Association.

The subject of fire prevention will be here treated as it applies to conditions in the United States, and from the viewpoint of those, who through practicable means seek to reduce the present enormous fire waste. The problem, as it exists in this country, must be appreciated. We do not possess Old World conditions, where buildings are comparatively small in area, low, generally of solid masonry construction, with small window openings, and frequently separated by wide avenues and parks. Our towns, with few exceptions, have been built hurriedly and cheaply, using vast quantities of wood in floor and roof construction, if not in walls, this material being the most available and least expensive. Consideration has been given only to the needs of the present and immediate future. Speaking generally of city districts, intelligent treatment of the individual risk as regards construction and fire extinguishment has been given only in occasional, yet important, instances, and the conflagration hazard has not been provided against. Where municipal building regulations exist they have been poorly drawn in respect to fire prevention, and sometimes peculiarly observed. It is apparent the desire for better things must be stronger in the hearts of those most interested before any radical reform takes place.

The time has arrived, however, when in many large cities the property owner feels the need of greater security against fire, and complains under the burden of the insurance tax which, although heavy, is claimed to be inadequate, so far as central city districts are concerned. Engineers with the insurance companies are now studying these conditions in detail, and, with the combined interest of all pointing toward intelligent improvement, the present generation may hope to see a change for the better.

[404] 
"Fire prevention," broadly regarded, suggests three general lines of effort, each one of which demands the detailed and prolonged study of those intending to qualify as fire protection engineers or fire insurance underwriters:

(1) Preventing the origin of fires; (2) controlling fires where they occur ; (3) preventing the spread of fires from "risk" to "risk." This includes the following up to best advantage and restriction of such a spreading fire once it is under way. By a "risk" we refer to a property manifestly all subject to one fire, as a building and its contents.

A consideration of these three features points to a further subdivision as follows:

r. Causes which originate fires: Incendiarism, common hazards and special hazards.

2. The individual "risk" at which the fire originates: Planning, construction, occupancies, fire extinguishing facilities, fire notification facilities, maintenance of such facilities, inspections and salvages.

3. Exposure and conflagration possibilities from grouped risks, due to fire extending from one building to others in view of the following causes: (a) Fire in the individual risk passing beyond control; $(b)$ effect of the size of the risk, viz., the quantity of the combustible comprising the building and contents subject to burning at one time; $(c)$ fire extending out through wall openings and through roofs; $(d)$ fire entering through wall openings and through roofs; $(e)$ fire spreading, due to the falling of burning floors and contents; $(f)$ fire spreading, due to the falling walls of a burning building; $(g)$ influence of street widths and open areas; $(h)$ influence of prevailing winds; $(i)$ the "range" of or territory affected by heat waves and fire brands; $(j)$ adverse conditions of the weather or of the fire facilities at the time of fire.

Such consideration as can be given this very large subject will consist in running through the topics above outlined and briefly commenting on each.

\section{Incendiarism.}

This is frequently the cause of a fire. First, we have the "direct moral hazard," where a property is fired by the owner for gain. Second, the "indirect moral hazard," where the owner may not be 
prospering or permanently located, and has little or no incentive for safeguarding hazards, keeping premises in repair and maintaining fire appliances, thus allowing the physical hazard to become abnormally high. Third, the outside "incendiary" who daily causes much fire waste, as the demented "firebug," the tramp, and the small boy who likes to see the fire department turn out.

The elimination of these hazards is impossible. Their restriction, however, can be somewhat brought about by the engineer in safeguarding fire extinguishing and fire notification systems against malicious tampering; by the fire insurance companies through a continuation and extension of their examination of the assured's prosperity and past records; and by the community in providing strict laws and penalties, and enforcing them through an honest fire marshal's department.

Occasionally a theorist advances in public print a suggestion that incendiarism is engendered by overinsurance, and could be entirely remedied by the insurance companies insuring for, let us say, not exceeding three-quarters of the value. The record of fire losses has clearly shown that moral hazard is frequently found among assured of means and of high social standing or with excellent mercantile ratings. It is manifest, insurance companies do not extend indemnity where they realize a moral hazard exists. To offer insurance only to the extent of three-quarters of the value would be a great hardship upon the man, fortunately in the vast majority, who does not wish a fire, and would, in event of total loss, bankrupt many property owners of limited means.

The American public is not prepared for state or national laws thus limiting the amount of indemnity that can be collected to a percentage of the amount of loss. The insurance companies would doubtless erttertain such a proposition from an assured at any time he might see fit to make it, and it is clear could issue policies on many properties at a reduced rate with such a provision made therein.

Common Hazards.

These are fire causes common to most risks, the chief of which are here noted:

Heating and Lighting.- These subjects are most carefully specified and described in the underwriter's requirements, and involve 
the consideration of chimneys, stacks, flues, trimmer arches, fireplaces, stoves, furnaces, boilers, heaters, grates, steam and hot water pipes, fuel and fuel storage, ashes, sparks and oil stoves.

Consideration of the lighting hazard involves knowledge of the rules, regulations and experiences in relation to the providing of artificial illumination by means of electricity, gas, oil, gasoline, acetylene, candles and torches, both fixed and portable equipments.

Housekeeping.-Carelessness in respect to the above causes perhaps the greatest number of fires. Miscellaneous refuse, commonly swept up on the floor constitutes an unknown, complex hazard. Often materials are contained therein which, when packed into a receptacle, are likely to ignite spontaneously within a few hours. Cleanliness is conducive to low fire cost.

Lightning, matches, tobacco smoking and fireworks complete our list of the most important common hazards.

\section{Special Hazards.}

These are hazards peculiar to different occupancies, and as a rule associated with some process of manufacturing, although they are conspicuous in certain other classes, as, for instance, theatres and hotels.

The underwriters, guided by their fire experiences of many years, have listed these hazards as they obtain in each class of occupancy, stating how they should be located, protected and minimized. This branch of our work is of itself quite sufficient to furnish a lifetime occupation. The chief of these special hazards appear in some one of the following six groups: (r) Artificial heating, as driers and ovens; (2) spontaneous ignition; (3) explosions of dust, chemicals or vapors; (4) textile stock preparing; (5) boiling over or ignition of inflammable compounds, fats and similar substances, and (6) friction at shafting and machinery.

\section{Planning a Building.}

Too little attention is given this subject from a fire prevention viewpoint. Care must be taken to isolate or best provide for the special hazards and occupancies; to obtain light and air without creating exposure or draught conditions; to make such reasonable subdivision of the risk into several fire areas as is compatible with 
the occupancy; to arrange communication from floor to floor for passengers and freight, and yet make provision against a fire seeking the same avenues; to locate elevators and stairs at margins of rooms rather than at inaccessible situations; to consider available fire protection when planning the height or the depth of a building; to make suitable provision for the weights of fire service tanks, the location and accessibility of pumps and boilers; and the elimination of light wells, also of windows in angle walls which would allow fire communication.

\section{Construction.}

There are four general classes under this heading: Fireproof, semi-fireproof, slow burning and ordinary. Specifications in numercus items exist in relation to each, not only for the construction of buildings, standard in their class, but also for the partial improvement of sub-standard conditions.

Fireproof buildings are those of steel cage construction, with all of the metal structural members safely insulated against heat from within or without the building, or they are of reinforced concrete construction with the reinforcing members similarly insulated. It is important that such buildings have all stairs, elevators and other communications between floors safely encased in fireproof cut-off shafts, and that all nearby horizontal tiers of windows be fitted with wire glass in fireproof frames. Otherwise, a fire in any one story of such a building-forced by the floor construction to burn out through the windows-may communicate on the outside of the building to the stories above through similarly situated windows.

A fireproof building should in reality prove itself a perfect stove, allowing its contents to burn out with a minimum of damage to the building. Many structures bearing the name "fireproof" fall far short of this. The early examples, as might be expected, contained many inadequate features, due to lack of appreciation of the problem involved; yet to-day just as poor structures are being erected, because the local building laws do not prevent, because they cost less, and because the owner and architect have not heeded the already well-developed fire experiences in this class. It is strange the way the public clings to its belief that things non-flammable are [408] 
fireproof, and somehow takes it for granted that a fireproof building will lend this quality to its contents.

In alluding to this subject one cannot well refrain from citing the lessons of the recent Baltimore conflagration, where the insurance loss on the fireproof buildings was in almost the same ratio as on the ordinary buildings and combustible stock, this being due, primarily, to the large damage done such buildings, and, in the second place, to the shortage of insurance to value on this class. Of the fireproof buildings involved in the Baltimore conflagration seven were so-called "skyscrapers," and of steel cage tile construction. Sixty-four per cent. of the value of these buildings was destroyed by the fire. In this connection it should be borne in mind that these seven buildings were of office occupancy, and did not contain certain amounts of combustibles which should cause a prolonged interior fire. As a matter of fact conflagrations swept in and out of some of these buildings in less than one-half an hour. Many experts studying these results believe that had the structures been crowded with combustible stocks-as with mercantile and manufacturing occupancies, which would have caused an intense internal fire for hours-the structures would have been even more seriously damaged, even to the extent of collapse and total destruction. In the conflagration these buildings were without any form of fire protection, as the public clepartment could not have approached them had they desired, due to the burning of surrounding properties. On the other hand, it is fair to remark that at least a number of these buildings contributing to the 64 per cent. damage average were of inferior quality, and by no means represented the excellence of construction which is to-day employed quite freely by those who are willing to pay the price.

The National Board of Fire Underwriters' Committee on the Baltimore conflagration has tabulated the following in relation to the chief fire proof buildings, involved, showing the following distribution of building value: Foundations, 6 per cent.; steel frame, I4 per cent. ; mason work, 30 per cent. ; equipment, 20 per cent., and trim and finish, 30 per cent. In addition the general expenses attending the fire equalled 5 per cent. of the total value. These include miscellaneous items, architects' fees, permits, surveys, insurance and cleaning out débris after the fire.

It is manifest that the trim and finish must be all subject to loss [409] 
or damage by fire, although the percentage of value therein to the total sound value of the building can be wisely reduced in many new structures from 30 per cent. to, let us say, 20 per cent., subject to fire damage.

The equipment is not likely to all be subject to loss; in fact in the statistics from which we are quoting but 62 per cent. of the 20 per cent. of sound value found in the equipment item was a loss. We will estimate that in a model building the value of the equipment subject to loss can be figured at Io per cent.

Fifty-three per cent. of the mason work on these Baltimore "fireproofs" was lost through the fire, that is to say, 53 per cent. of 30 per cent. of the total sound value. Perhaps in a model building this could be reduced to Io per cent.

From this we learn that there is at least 40 per cent. of the value of a well constructed fireproof type building which cannot, in any event, be considered as exempt from fire loss.

Semi-fireproof buildings are constructed with non-flammable material, but with structural or tension metal members, either entirely exposed or not properly insulated against heat. Sometimes metal lathing and plaster covering are used to conceal the metal. These buildings are occasionally erected because they are cheaper than the above type, and yet comply with the prevailing building code, or because they are for dwelling house, office or similar occupancy, where the assumption is that the amount of combustible within the building is not sufficient to generate heat enough to impair the metal portions of the structure.

Slow burning buildings, sometimes called "mill construction," have floors without openings, built of plank laid on wide spaced heavy timbers. No metal is allowed in this type of construction. The plank flooring must in no case be less than three inches in thickness, and there must be a tight top flooring, with waterproof paper between. Absolutely no openings must be built or cut through these floors. The planking is laid on timbers spaced from five to twelve feet apart, which in turn rest on stout wooden posts of prescribed dimensions.

The idea of this type of construction is to have each story separated from other stories by a tight barrier of considerable thickness, the ceilings presenting smooth surfaces of plank and timber, with as few edges and angles as feasible. It requires several hours 
under ordinary conditions to burn through a mill constructed floor, even when the rooms contain large quantities of combustible stock, as in textile mills. Ordinary buildings have wood joist board covered floors and roofs as distinct features.

Under "construction," altogether the most important feature to provide against, is the vertical opening; that is to say, an opening through floors for stairs, elevators or for other purposes. All such should be strictly tabooed in all types of construction, and their objects served by communication only through fireproof shafts, with approved fire protecting coverings at necessary story openings.

\section{Fire Doors, Shutters and Wire Glass Windows.}

This subject has received extended treatment, and even to-day is not in a finally satisfactory shape, yet the underwriters' doors can be depended upon to keep out nearly all fires when placed on both sides of the wall and fully closed.

The type of door and shutter now most in use is of wood covered with specially lock jointed tin plates, and fitted throughout with special hardware. In a fire the wood carbonizes slowly, and the gas therefrom escapes through the lock joints of tin, without accumulating a pressure and throwing off the sheets. In severe fires the wood is all burned out and the charcoal falls to the bottom of the tin covering, but the latter holds together as a barrier at the wall opening, except where it may have been to some extent bent away from the margins of the opening, but the protection of this sheet of metal, plus the less severely damaged door on the other side of the opening, is sufficient to prevent the passage of the fire.

The rapid development of wire glass and frames to hold it promises to revolutionize window protection. Such windows are always in place, and, unlike shutters, do not constitute an additional care, for the nightly closing of shutters serves no purpose except that of fire protection. Again, shutters, particularly the tin clad wooden pattern, disintegrate under the influence of the weather, and at best require considerable expense in the way of paint and repairs. On the other hand wire glass radiates heat, and, when subjected to the heat of a severe exposing fire, combustible goods at the rear of the glass may become ignited, and in this respect the glass is inferior to a well designed shutter, once the latter is closed and properly fastened. 


\section{Occupancies.}

Isolation of hazards has been referred to under "Construction." In addition to this the relative location of processes is of importance. As an example, in full process knitting mills the card rooms-in which fires most frequently occur-have often been located immediately above the finishing rooms, in which exists a large accumulation of finished goods. Under these conditions every time a fire occurred in the card room a water damage of vastly larger proportions resulted in the finishing room beneath. For the economical operation of the plant it was not necessary that the card room should be over the finishing room.

Attention should be given to the placing of stock on skids, so as to be above the floor and thereby avoid needless water damage, and to keeping stock in cases or "flat" as much as possible, opening up no more than necessary. Large hollow piles of combustible stock are particularly to be avoided; as it is practically impossible to put out a fire spreading within such piles. Needless draping of combustible merchandise about elevators and stair shafts, from counters to ceiling and in light wells, frequently occurs. In many of the department stores holiday displays-such as a cotton wad snow storm throughout an entire light well-have been fearful and wonderful sights. Frequently, through lack of thought, a storekeeper or manufacturer will bring some excessive hazard into his busines not necessary thereto, as a stock of fireworks in a drug store, dynamite in a hardware stock or several barrels of benzine in a factory where only a few quarts are needed daily, and the remainder should be stored at a safe distance. The uses of rooms and buildings, that is to say, their occupancies, are legion, and each -at least theoretically—of relatively different fire cost importance.

\section{Fire Extinguishing Facilities.}

We understand a substance to be "burning" when its temperature has been raised to or above the ignition point of the substance, and provided sufficient oxygen is present to support the combustion. Inflammable substances are those having a low ignition point. The burning of such substances raises the temperature of similar adjoining substances so that they in turn burn, thus extending the fire. 
In fires which concern us the oxygen in a required amount is supplied from the air combining with the inflammable materials at their respective ignition points. Chemical action results; heat and the fire with which we have to contend are produced; also gases, which burn and constitute flame; and smoke, consisting of particles of the substances which, partly consumed, are carried away by the currents of hot air. To extinguish a fire we must, therefore, either reduce the temperature of the burning substance below its ignition point or exclude from it the air. The fire protection engineer is concerned with the most practical method of accomplishing this end.

From the time of Hero, who, about 150 B. C., describes the construction of a two cylinder fire pump, up to the present day, water has constituted the only extinguishing means of any importance, and bids fair to so remain for an indefinite period in the future. Nothing more efficacious than the syringe "squirt," water pail pump and hand-brake fire engine were developed and put in practice until the middle of the nineteenth century. Chemical extinguishers of little value were used in the eighteenth century; while the portable hand pump, draughting from a trough of water, was in use in Germany, England and elsewhere during the middle and latter part of the eighteenth century. The first stęam fire engine was used in London in 1829 , and in the United States in 1853 . Flexible leather fire hose was made in Amsterdam in 1672. A Philadelphia manufacturer, during 1808 , brought out a copper riveted leather hose. During 1720 fire hose of hemp was manufactured in Germany; while rubber fire hose was first introduced in England as late as 1827 . The first electric fire alarm system was installed in the city of Boston, Mass., in 1852, although two years previous the Morse telegraph system had been employed for sending fire alarm notices in New York City. In the last fifty years the radically increasing values in large single risks and in congested city districts, and the combustible construction and disregard of sound protection principles have brought about rapid strides in the development of fire extinguishing appliances in this country.

The importance of checking a fire in its early stages can be readily realized. Five minutes' start through unstopped vertical openings may spread the flames to all portions of a building, and such a large quantity of combustible contents and building material may be put on fire at one time as to exceed the ability of the fire 
department to cool off the mass faster than the fire spreads to new material. One pound of wood fuel will evaporate about one gallon of water, and a large area of crowded buildings exists in many localities of nearly every city where, if a fire breaks out, the question as to whether a total loss of the one building or a conflagration in the neighborhood results, depends upon a few minutes or seconds difference in the time the water is put on the fire.

Another point to be borne in mind is that with a considerable fire under way it is very hard for the department to get near enough to have their hose streams search out the burning mass; they are often deceived by the smoke and fail to locate the heart of the fire until it is too late. Hose streams directed from the street cannot effectively penetrate the fifth or higher stories of usual buildings or lower stories of very deep structures, and movable water towers as now used by the public departments add but a few stories to the effectiveness of such streams. It is apparent that frequently located fixed metal standpipes must be introduced in order to allow of anything like an effective concentration of public hose streams upon a fire burning in the upper stories of a high building. It is variously estimated that from six-tenths to nine-tenths of the water thus discharged through hose streams is wasted. That occasionally disastrous fires result is not the fault of the fire department but of those who allow conditions to exist which may bring conflagrations to pass at any moment.

\section{Automatic Sprinklers.}

To obtain the desired control of fire the following are needed: (I) A prompt application of water, prompt almost to the extent of being instantaneous with the fire outbreak; (2) the discharge of the water locally precisely at the seat of the fire, and distributed so that the least amount of water will do the greatest amount of good; (3) an immediate notification that the fire is in progress.

These conditions might at first thought be considered quite impossible of fulfillment. This instance is an exception in that the ideal is not only possible but practicable; in fact, an undisputed ability to meet these specifications is well proven.

We find such protection only in the modern sprinkler installation, which operates automatically and immediately upon the out- 
break of fire, confines its operations to the very location where the fire is occurring, and gives prompt fire alarm to any point desired through the medium of the sprinkler pipe alarm valve.

Properly installed automatic sprinkler service is altogether the best known and most efficient means of fire fighting. We have had for some twenty years the sensitive automatic sprinkler protection, and yet to-day its possibilities are not realized. This type of protection is destined within a short time to be generally regarded as the apparatus in chief for the extinguishment of fires. It will be generally found in most buildings having combustible construction or contents of from moderate to large values. This branch of fire protection, more than any other, has been the subject of the most careful research, test and specification. It already has a considerable literature available to the student, covering both engineering features and fire loss statistics.

\section{Fire Pails.}

These constitute the simplest, best understood and most used means of fire extinguishment; hence the careful requirements on the subject, which are more extensive than one might assume. Other fire extinguishing apparatus coming under detailed specifications are the following: Public and private water works system, cast iron underground piping, post hydrants, public and private fire department, fire department $2 \frac{\mathrm{T}}{2}$ and 3 inch hose, $25 / 8$ inch cotton, rubber lined private outside hose, $2 \mathrm{I} / 2$ and $\mathrm{I}$ inch unlined linen hose, playpipes, spanners, hose houses, carbonic acid gas chemical extinguishers, monitor nozzles, stationary steam fire pumps, rotary and centrifugal pumps, electrically driven pumps, pressure and gravity tanks and cisterns and valves and fittings.

\section{Fire Notification Facilities.}

In the endeavor to bring all available fire facilities into operation as quickly as possible, the public manual electric fire alarm service has been highly developed. Automatic fire alarm systems, extending to all portions of the building, are much in use. An electrical supervisory notification system for the different parts of an automatic sprinkler system is now coming upon the market, whereby too high or too low a temperature or water level or air pressure in a 
gravity or pressure tank, the partial closing of a valve or the flow of any water through the system, will immediately give detailed notice at the central station. In addition to the above the old-fashioned inefficient watchman is still employed, and he in turn is watched by a central station or a stationary or portable clock system. We also have the alarm valve on the automatic sprinkler system above mentioned.

\section{Maintenance and Inspection.}

"Improved Risks"-those having a considerable amount of complex devices and apparatus for the notification and extinguishment of fire-require to have such systems maintained at all times. To see that this is done the property owner has an organized system of inspection, which in turn is checked up by the less frequent but more thorough insurance inspections. The inspection of risks, not long since given over to the inexperienced, is now assuming almost the position of a profession. Graduates of technical schools in large numbers are obtaining remunerative employment in this occupation, and the general character of the work is being advanced.

\section{Salvages.}

In event of a fire occurring it is clearly clesirable to save as much of the value as possible. To this end sub-division of risks, tight floors, smoke ventilation of buildings, drainage of floors and basements and coverings for stock are provided; in addition to which salvage corps are maintained in most cities, who devote themselves to this work.

\section{Exposure and Conflagration.}

Exposure from an immediately located building represents an entirely different condition from a conflagration district exposure. Conflagrations must, however, be prevented largely through reduction of the immediate exposure hazard.

It was noted above that a large quantity of combustibles in any one risk, if it become afire at one time, may likely exceed the capacity of the public and private fire fighting facilities. Such being the case it is beyond control in the one risk. The fire will then in time, except with a fireproof building, burn out the floors and roofs, 
allowing them to fall to the ground, together with such contents as at that time are unburned. This is likely to cause a great wave of heat and a shower of brands to extend to nearby properties which may have been, up to that time, unmenaced. Again, it is likely to tear down the walls of the building, which, if blank, may have constituted an excellent fire barrier, or the walls in falling may topple out and open up exposed risks which have until then withstood the fire.

The wind prevailing at the time of such a fire beyond control, is an important factor, for if the fire communicates to other buildings, and, spreading, becomes a conflagration, the wind will determine to a large degree the direction and hence the extent of the area to be destroyed. In such a conflagration the area immediately in front of its progress for.from a few hundred feet to at times several blocks may be rendered untenable by the heat waves, gases and firebrands driven in front of the advancing conflagration. It is at such a time impossible to fight the fire from such a point, in which event resistance must solely depend upon blank walls, fire protecting window coverings, non-flammable roofs, and, to some extent, fire protection at individual risks.

The public department, through a large number of high pressure hose streams, will often be able to surround a fire and prevent its general spread, although it may be beyond control in the building where it originates; or, failing in this endeavor, they may follow on either side of a spreading fire and hem it in, preventing back fires and local subsidiary conflagrations. Adverse conditions which the public department has to meet must, however, be realized, such as unusual snow fall, extreme cold weather in certain sections of the country, or gales of wind; street repairs which prevent access of apparatus or department to hydrants or buildings; water supply system locally impaired, due to drought, repairs or extensions, or carelessly closed gate valves.

It is therefore seen that, to use reasonable precaution against the conflagration hazard, we must-

First.-Curtail the size of risks so they cannot contain in any one section an amount of combustible which, if on fire at one time, is likely to place the district beyond control of existing facilities.

Second.-Extend over most occupancies the protection of a well designed automatic sprinkler service. 
Third.-Positively prevent communication from floor to floor of a building except through fireproof shafts.

Fourth.-All exterior windows, including all windows on street fronts, except outside open areas, should be fitted with fireproof wire glass windows, and, in addition, where exposures are severe, with approved shutters.

Fifth.-The public water and fire department facilities, in most instances ill prepared to meet severe conditions, should be radically increased. This may involve the introduction of a modern, adequate and direct fire pressure water supply.

All these things and many more are directly a part of the broad subject of "fire prevention." I wish only to give a glimpse of these various avenues of investigation and research, and will express the hope that many will find the subject inviting, take occasion to pursue it diligently, and become factors in the reduction of needless fire waste, as the time has come when good men interested in this cause are needed. 